\title{
Global Screening of Salmonella enterica Serovar Typhimurium Genes for Desiccation Survival
}

\section{OPEN ACCESS}

Edited by:

David Rodriguez-Lazaro, University of Burgos, Spain

Reviewed by: Jeremiah Johnson, University of Tennessee, Knoxville,

United States Marcello Trevisani,

Università di Bologna, Italy

*Correspondence:

Rabindra K. Mandal

rabindra.manda/@/ouisville.edu

${ }^{\dagger}$ Present Address:

Rabindra K. Mandal,

Department of Microbiology and Immunology, University of Louisville,

Louisville, KY, United States

Specialty section:

This article was submitted to Food Microbiology,

a section of the journal

Frontiers in Microbiology

Received: 04 May 2017

Accepted: 24 August 2017 Published: 08 September 2017

Citation:

Mandal RK and Kwon YM (2017)

Global Screening of Salmonella enterica Serovar Typhimurium Genes

for Desiccation Survival.

Front. Microbiol. 8:1723.

doi: 10.3389/fmich.2017.01723

\author{
Rabindra K. Mandal ${ }^{1 * t}$ and Young M. Kwon ${ }^{1,2}$ \\ ${ }^{1}$ Department of Poultry Science, University of Arkansas, Fayetteville, AR, United States, ${ }^{2}$ Cell and Molecular Biology \\ Program, University of Arkansas, Fayetteville, AR, United States
}

Salmonella spp., one of the most common foodborne bacterial pathogens, has the ability to survive under desiccation conditions in foods and food processing facilities for years. This raises the concerns of Salmonella infection in humans associated with low water activity foods. Salmonella responds to desiccation stress via complex pathways involving immediate physiological actions as well as coordinated genetic responses. However, the exact mechanisms of Salmonella to resist desiccation stress remain to be fully elucidated. In this study, we screened a genome-saturating transposon (Tn5) library of Salmonella Typhimurium (S. Typhimurium) 14028s under the in vitro desiccation stress using transposon sequencing (Tn-seq). We identified 61 genes and 6 intergenic regions required to overcome desiccation stress. Salmonella desiccation resistance genes were mostly related to energy production and conversion; cell wall/membrane/envelope biogenesis; inorganic ion transport and metabolism; regulation of biological process; DNA metabolic process; ABC transporters; and two component system. More than $20 \%$ of the Salmonella desiccation resistance genes encode either putative or hypothetical proteins. Phenotypic evaluation of 12 single gene knockout mutants showed 3 mutants (atpH, atpG, and corA) had significantly $(p<0.02)$ reduced survival as compared to the wild type during desiccation survival. Thus, our study provided new insights into the molecular mechanisms utilized by Salmonella for survival against desiccation stress. The findings might be further exploited to develop effective control strategies against Salmonella contamination in low water activity foods and food processing facilities.

Keywords: Salmonella, desiccation stress, genetic determinants, Tn-seq, low water activity food

\section{INTRODUCTION}

Salmonella is one of the most common causes of foodborne illness worldwide. It can withstand a spectrum of hostile milieus such as, desiccation found in natural and food industry settings (Spector and Kenyon, 2012). Salmonella can persist in the low water activity (low- $\mathrm{a}_{\mathrm{w}}$ ) environment for extended periods of time. Salmonella is also able to survive from several weeks and months, even to years in dry foods (chocolate, hard cheese, dried eggs, infant dried milk, salami, halva, almonds kernels, pecans, dry confectionery raw materials, and peanut-flavored candy; Beuchat and Heaton, 1975; Kotzekidou, 1998; Hiramatsu et al., 2005; Uesugi et al., 2006; Bell and Kyriakides, 2008; Komitopoulou and Peñaloza, 2009; Gruzdev et al., 2012a) and dry surfaces (desiccated paper discs, plastics, and eggshells; Braun et al., 1999). Globally, there were 7,315 reported cases of bacterial 
outbreak illness and 63 deaths due to consumption of contaminated low $-\mathrm{a}_{\mathrm{w}}$ foods and spices during the period from 2007 to 2012. Salmonella alone was accountable for $94 \%$ of the low- $\mathrm{a}_{\mathrm{w}}$ food recalls in the U.S. and $53 \%$ of outbreaks worldwide in the above 6 years (Farakos and Frank, 2014).

Additionally, exposure of Salmonella to low water activity increases cross-protection against other stresses including heat, ethanol, sodium hypochlorite, dodecyl dimethyl ammonium chloride, hydrogen peroxide, $\mathrm{NaCl}$, bile salts, and $\mathrm{UV}$ irradiation (Gruzdev et al., 2011), which ultimately makes the prevention and control strategies less effective. Food industry faces a significant challenge to rein Salmonella burden from dry foods and spices without damaging the organoleptic properties. Control of Salmonella contamination in the low- $\mathrm{a}_{\mathrm{w}}$ foods might be improved marginally through improvement in the hygiene and rapid and sensitive detection of Salmonella in food and food processing environments. However, it is more critical to understand the genetic mechanisms of Salmonella resistance in low- $\mathrm{a}_{\mathrm{w}}$ environment for improvement of public food safety associated with low- $\mathrm{a}_{\mathrm{w}}$ foods (Beuchat et al., 2013).

In the last few years, considerable progress has been made to unveil the underlying mechanisms of Salmonella tolerance against desiccation using transcriptome analysis (Deng et al., 2012; Gruzdev et al., 2012b; Li et al., 2012; Finn et al., 2013b). The immediate response of bacteria to low low $-\mathrm{a}_{\mathrm{w}}$ foods environment involves balancing the internal osmotic pressure to keep them viable. Commonly believed mechanism for desiccation tolerance in Salmonella include the followings: increased potassium influx by $k d p$ transporter; increased expression of osmoprotectant transport (proPU and osm $U$ ), glutamate and trehalose synthesis; and up-regulation of fatty acid catabolism, Fe-S cluster, sigma factors $(r p o E$ and $r p o S$ ), and ompC. Additionally, cellulose and curli fimbriae may play an important role in desiccation resistance in Salmonella. However, Finn et al. (2015) reported that $S$. Typhimurium genes differentially expressed in response to different humectants, agents that reduce water content of food products, do not simply reflect low low- $\mathrm{a}_{\mathrm{w}}$ but rather are linked to specific humectants (Finn et al., 2015). In addition, differentially expressed transcripts in a cell do not necessarily reflect the functional role of the genes at the given condition. Instead, the presence of these transcripts can be a reflection of the predictive adaptation of bacteria where the expressed transcripts may not have any functional roles in their current milieu (Tagkopoulos et al., 2008; Mitchell et al., 2009). Furthermore, the expression-based analysis does not provide insight into genes that are constitutively expressed or gene for which expression of the encoding proteins is controlled by post-transcriptional modifications. However, these limitations of expression-based analysis can be largely overcome by a more direct functional screening approach such as, transposon sequencing (Tn-seq) of saturated mutant libraries employed in this study.

In this study, for the first time to our knowledge, we used a Tn-seq approach to investigate the genetic determinants required for desiccation survival in $S$. Typhimurium. We screened a genome-saturating Tn5 mutant library of $S$. Typhimurium 14028 s and identified 61 fitness genes required for survival of $S$. Typhimurium under a desiccation stress.

\section{MATERIALS AND METHODS}

\section{Bacterial Strains and Growth Conditions}

Salmonella enterica serovar Typhimurium 14028S, a spontaneous mutant resistant to nalidixic acid (NA), was used for the transposon insertional mutagenesis. Bacteria were grown in Luria-Bertani (LB) medium or LB agar plates at $37^{\circ} \mathrm{C}$ and stored at $-80^{\circ} \mathrm{C}$ unless indicated otherwise. NA (ICN Biomedicals Inc., Aurora OH, USA) and Kanamycin (Km, Shelton Scientific, Inc. CT, USA) were used at $25 \mu \mathrm{g} / \mathrm{ml}$ and $50 \mu \mathrm{g} / \mathrm{ml}$, respectively. Bacteria were incubated on shaking rack at $225 \mathrm{rpm}$ when required. Polystyrene disposable petri dishes $(60 \times 15 \mathrm{~mm}$; VWR International, USA) were used for screening of the mutant library under a desiccation stress.

\section{Construction of Tn5 Mutant Library}

Electrocompetent $S$. Typhimurium cells were prepared and transformed with EZ-Tn $5<\mathrm{KAN}-2>$ Tnp transposome complex (Epicenter BioTechnologies, Madison, WI, USA) following the manufacturers' instructions. Electroporation was performed using $0.1-\mathrm{cm}$ cuvettes in a Micropulser electroporator (Bio-Rad Laboratories, Inc., Mississauga, Ontario, Canada) with a field strength of $2450 \mathrm{~V}$. The electroporated cells were immediately resuspended in $500 \mu \mathrm{l}$ of SOC medium (Quality Biological Inc., Gaithersburg, MD) and incubated for $1.5 \mathrm{~h}$ at $37^{\circ} \mathrm{C}$ on a shaking rack $(225 \mathrm{rpm})$. Then, the Tn5 mutant cells were plated on LB plates supplemented with double antibiotics (NA and $\mathrm{Km}$ ), which were then incubated overnight at $37^{\circ} \mathrm{C}$. We collected and combined $\sim 370,000$ Tn5 mutants from three transformations, making it a highly complex library. The mutant cells were scrapped off LB plates in 1X phosphate buffered saline (PBS; $\mathrm{pH} 7.0)$ and stored in $50 \%$ glycerol at $-80^{\circ} \mathrm{C}$.

\section{Screening of Tn5 Mutant Library During Desiccation Stress}

The Tn5 complex library stored at $-80^{\circ} \mathrm{C}$ was thawed on ice and $300 \mu \mathrm{l}$ of the library was diluted in $60 \mathrm{ml} \mathrm{LB}$ and incubated at $37^{\circ} \mathrm{C}$ on a shaking rack for $30 \mathrm{~min}\left(\mathrm{OD}_{600}=0.135\right)$. Then, bacteria were collected by centrifugation at 5,500 rpm for 8 min at room temperature (RT) and resuspended in $50 \mathrm{ml}$ PBS $\left(\mathrm{OD}_{600}=0.143\right)$. Ten milliliter from this mutant suspension $\left(t_{0}\right.$ time point) were centrifuged and the bacterial pellet was saved for DNA extraction (Input pool; IP).

For negative selection of Tn5 mutants during desiccation survival, $10 \mathrm{ml}$ of suspension from $t_{0}$ was centrifuged and resuspended in one $\mathrm{ml}$ PBS $\left(\sim 8.0 \times 10^{8} \mathrm{CFU} / \mathrm{ml}\right)$. Then aliquots of $100 \mu \mathrm{l}$ were placed at the center of 10 petri plates $(60 \times 15 \mathrm{~mm}$ size) and air-dried with the lid open inside a biosafety hood with the blower on for $4 \mathrm{~h}$. Then, the plates were covered with the lids and incubated at RT for $24 \mathrm{~h}$. The desiccated cells were collected from all the 10 petri plates by resuspending them in one $\mathrm{ml}$ PBS buffer for each petri plate (in total $10 \mathrm{ml} \mathrm{PBS}$ ), which was then concentrated in one ml PBS. Bacterial cells (100 $\mu$ l aliquot) were plated on $10 \mathrm{LB}$ plates (NA and $\mathrm{Km}$ ) and incubated overnight. The cells were collected from all 10 plates in PBS, centrifuged and the pellet was stored at $-20^{\circ} \mathrm{C}$ (Output pool; OP). 


\section{DNA Library Preparation for Illumina Sequencing}

Genomic DNA (gDNA) was extracted from IP and OP (100 $\mu \mathrm{l}$ aliquot of each pellet) using QIAamp DNA Mini Kit (Qiagen, Valencia, CA, USA) following manufacturer's protocol. The DNA was quantified using a Qubit 2.0 Fluorometer (Life Technologies, Carlsbad, CA). DNA libraries were prepared following the protocol developed in our lab (Dawoud et al., 2014) with some modifications. For detailed information, see Supplementary Protocol 1. Briefly, linear extension PCR was done to enrich the Tn5-juction sequences using a single primer specific to Tn5 transposon (7 bp upstream of invert repeat 2, IR2). The linear extension products were purified and C-tail was attached using terminal transferase (New England BioLabs, Ipswich, MA). C-tailed products were purified and exponential PCR was performed using barcoded forward primer and poly-G primer with an attached Illumina adapter (HTM primer; Table S1). The PCR products were separated on $1.5 \%$ agarose gel and the amplicons ranging from 300 to $500 \mathrm{bp}$ were gel-purified. The purified DNA from IP and OP were mixed in an equal quantity (10 ng), and sent for Illumina sequencing using HiSeq 2000 single end read option with 100 cycles (Center for Genome Research and Biocomputing, Oregon State University, Corvallis).

\section{Data Analysis}

Sequencing reads obtained from the Illumina HiSeq 2000 single end read were analyzed using Analysis of high-Resolution Transposon-Insertion Sequences Technique (ARTIST; Pritchard et al., 2014). Briefly, demultiplexed reads with 20 bp transposon junction sequence were aligned against $S$. Typhimurium 14028s complete genome (accession number: NC_016856.1) using Bowtie version 0.12.7 (Langmead et al., 2009). The sequence alignment map (SAM) file was fed to ARTIST pipeline to identify conditionally essential genes (CEGs) using Con-ARTIST (Pritchard et al., 2014). Tn5 insertion reads were assigned to $100 \mathrm{bp}$ windows of $S$. Typhimurium genome. Uncorrected raw data were used to normalize IP and then reads were compared between IP and OP using Mann-Whitney U test (MWU). The MWU results were used to train hidden Markov model (HMM) to predict the likelihood of loci to be conditionally essential or non-essential in OP $(p<0.01)$. Only the insertions in the middle $80 \%$ (excluding $10 \%$ at both $5^{\prime}$ and $3^{\prime}$ ends) of the protein-coding genes were considered to inactivate the protein functions and thus included in the analysis with cutoff $>8$ fold and $>2$ fold for depleted and enriched loci, respectively.

\section{Phenotypic Evaluation of Single Gene Knockout Mutants}

Single-gene knockout mutants of S. Typhimurium 14028s were ordered from the BEI Resources (www.beiresources.org; Porwollik et al., 2014). The mutants from 96-well plates were streaked on $\mathrm{LB}$ plates $(\mathrm{Km})$ and grown overnight at $37^{\circ} \mathrm{C}$. A single colony was picked and grown in LB broth $(\mathrm{Km})$ for each mutant, and the strains were stored at $-80^{\circ} \mathrm{C}$ in $50 \%$ glycerol. Twelve mutants were chosen based on the availability in our strain collection to represent the wide range of fold reduction in read numbers after the selection. Desiccation experiment was performed as described by Gruzdev et al. (2011) with some modifications (Gruzdev et al., 2011). A single colony of each mutant strain was picked from a LB plate with an appropriate antibiotic (NA for the wild type; Km for knockout mutants) and incubated in $10 \mathrm{ml} \mathrm{LB}$ broth with appropriate antibiotics aerobically overnight in standard conditions $\left(37^{\circ} \mathrm{C}\right.$ and shaking rack@225 rpm). Overnight grown bacteria were washed 3 times in $1 \mathrm{X}$ PBS at $4^{\circ} \mathrm{C}$ with centrifugation at $8,000 \mathrm{rpm}$ for $2 \mathrm{~min}$. O. $\mathrm{D}_{600}$ was adjusted to $0.4( \pm 0.05)$ in $1 \mathrm{X}$ PBS. Colony forming units (CFUs) were measured for the wild type and mutants. Fifty microliter of bacteria with adjusted $\mathrm{OD}_{600}$ (0.4) was then transferred to 96-microtiter well plates. The microtiter plate (with lid open) was placed inside a laminar flow hood with the blower on for $10 \mathrm{~h}$ to remove moisture. The bottom of the microtiter well was completely opaque after drying. After $10 \mathrm{~h}$ of drying the microtiter plate was covered with a lid and placed on the bench for additional $14 \mathrm{~h}$ at RT. Then $200 \mu \mathrm{l}$ of 1X PBS was added to each well and the plate was shaken for $30 \mathrm{~min}$ at RT. The desiccated bacteria were then released from the wells and resuspended in PBS by vigorously pipetting 15 times and collected in $1.5 \mathrm{ml}$ microcentrifuge tubes. The CFUs of the recovered viable cells was measured by plating the suspension on LB plates, followed by overnight incubation for each of the wild type and mutants. Three replications were performed for each strain. Survival (\%) for each strain was calculated as (Total CFUs recovered after desiccation/ Total CFUs added) ${ }^{\star} 100$.

\section{RESULTS AND DISCUSSION}

\section{Overview of the Selection Process and Illumina Sequencing}

In this experiment, we subjected a complex Tn5 library of $S$. Typhimurium with more than 350,000 mutants to a desiccation stress. The Tn5 library (IP) was air-dried for $4 \mathrm{~h}$ on petri plates inside a laminar flow hood and incubated at the room temperature for $24 \mathrm{~h}$. The number of Tn5 mutants before and after the desiccation selection were $8 \times 10^{8} \mathrm{CFU} / \mathrm{ml}$ and $8.7 \times 10^{6} \mathrm{CFU} / \mathrm{ml}$, respectively, indicating only $1.09 \%$ of the mutants were able to survive following the desiccation stress. This low recovery indicates the fact that desiccation is a harsh stress for survival of Salmonella. The desiccated Tn5 mutants were resuscitated on $\mathrm{LB}$ agar plates ( $\mathrm{Na}$ and $\mathrm{Km}$ ) under the standard growth condition. DNA was extracted from IP and OP and the Tn-seq amplicon libraries were prepared for HiSeq Illumina sequencing as described in Material and Methods. Illumina sequencing reads were demultiplexed based on a perfect match to sample barcodes and Tn5-junction sequences (20 bp) were extracted allowing some mismatches to the mosaic end of Tn5 (see Table S1). IP and OP had 10,842,764 and 5,516,907 reads, respectively, and more than 186,000 and 132,000 unique insertions, respectively (Table 1). The number of unique genomic sites $(186,621)$ disrupted by Tn5 transposon in IP was unexpectedly lower than the number mutants collected $(350,000)$ after electroporation of 
TABLE 1 | Summary of Illumina sequencing reads.

\begin{tabular}{lccccc}
\hline Library & $\begin{array}{c}\text { Total } \\
\text { reads }\end{array}$ & $\begin{array}{c}\text { Reads } \\
\text { mapped }\end{array}$ & $\begin{array}{c}\text { Unique } \\
\text { insertions } \\
\text { (UnqIns) }\end{array}$ & $\begin{array}{c}\text { Mean } \\
\text { reads/ Unqlns } \\
\text { ( } \pm \text { SE) }\end{array}$ & $\begin{array}{c}\text { Median } \\
\text { reads }\end{array}$ \\
\hline $\begin{array}{l}\text { Input pool } \\
\text { (IP) }\end{array}$ & $10,842,764$ & $\begin{array}{c}8,867,116 \\
(81 \%)\end{array}$ & 186,621 & $48.99 \pm 0.99$ & 20 \\
$\begin{array}{l}\text { Desiccation } \\
\text { (OP) }\end{array}$ & $5,516,907$ & $\begin{array}{c}4,248,156 \\
(77 \%)\end{array}$ & 132,631 & $33.18 \pm 0.13$ & 18 \\
\hline
\end{tabular}

the transposome complex. This might be due to replication of Tn5 mutants during $1.5 \mathrm{~h}$ of incubation in SOC medium for phenotypic expression immediately after electroporation. Moderate Spearman's correlation was observed between IP and OP $\left(R^{2}=0.85, p<0.0001\right)$ with $\operatorname{Tn} 5$ insertion frequency at the nucleotide level (Figure 1A; Table S2). Additionally, Tn5 transposons were randomly inserted throughout the entire genome without any noticeable genomic hot spots and amplification bias (Figure 1B). This reflects the good quality of the Tn5 mutant libraries (IP and OP) used for Illumina sequencing.

\section{Identification of Desiccation Resistance Genes}

We used Con-ARTIST pipeline to identify the resistance genes required for the desiccation stress tolerance in S. Typhimurium. Con-ARTIST identifies transposon mutants at the singleinsertion level and normalizes bottleneck effect enabling discovery of conditionally essential mutants at subgenic level (Pritchard et al., 2014). We identified 37 entirely conditionally essential (genes that contain significantly lower Tn5 reads throughout the entire coding regions) and 24 domain essential genes (genes that contain significantly lower Tn5 reads only in the certain region(s) of the entire coding sequences) that were required for survival during desiccation stress (Table 2). Among them, 10 genes encode putative proteins and six genes hypothetical proteins.

Further, we assigned desiccation resistance gene to the cluster of orthologous groups (COG) using EggNOG 4.5 (http:// eggnogdb.embl.de/\#/app/home) with target taxa Salmonella (Table 2, Figure 1C). The desiccation resistance genes having no orthologous were assigned to "No orthologous group." Equally highly abundant COGs were energy production and conversion (C), Cell wall/membrane/envelope biogenesis (M) (14.45\%), followed by post-translational modification, protein turnover, and chaperones $(\mathrm{O})$, and inorganic ion transport and metabolism (P) (both 11.48\%). Additionally, the desiccation resistance genes belonging to no orthologous group and function unknown were also relatively higher (11.48 and $9.84 \%$, respectively). The moderately abundant COGs were replication, recombination and repair (L), intracellular trafficking, secretion, and vesicular transport $(\mathrm{U})$, translation, ribosomal structure and biogenesis (J) and transcription $(\mathrm{K})$ ranging from 4.92 to $3.28 \%$. Furthermore, COGs with only one gene were amino acid transport and metabolism (E), carbohydrate metabolism and transport $(\mathrm{G})$, nucleotide transport and metabolism (F), signal transduction mechanisms (T), and defense mechanism (V). pagO belonged to both amino acid and carbohydrate metabolism and transport (Table 2; Figure 1C).

Additionally, we performed gene enrichment analysis using STRING database. The KEGG pathways and gene ontology (GO) process enriched for desiccation stress survival were searched in S. enterica LT2 (http://bit.ly/2cBK2e6). Genes that do not have orthologous genes in S. enterica LT2 background (STM14_1487, STM14_3165, and STM14_4725) were not considered. The abundant enriched categories included oxidative phosphorylation (ATP synthase genes), $\mathrm{ABC}$ transporters (fepCDG, siiF, and pstB), two component system $(g \ln D, r p o N$, and pagO), regulation of biological process ( $h f q, r p o N$, lepA, $d s b C$, dam, and $g \ln D$ ), DNA metabolic process (dam, dnaJK, and $x e r C D)$ and $\mathrm{O}$ antigen biosynthetic process $(r f b U$, and $r f b A)$.

\section{ATP Synthase}

All genes encoding the 9 subunits of ATP synthase were shown to be important for desiccation survival of $S$. Typhimurium (Table 2). ATP synthase is a highly conserved enzyme across the kingdoms of life with a pivotal role in chemiosmotic energy conversion. Bacteria when exposed to a desiccation stress, also suffer osmotic stress. Nouri and Komatsu (2010) found that during an osmotic stress in the soybean plant, $\mathrm{H}^{+}$-ATPases were the most prominent upregulated proteins, which help the plant maintain membrane potential for energy production, cell turgidity and intracellular $\mathrm{pH}$ (Nouri and Komatsu, 2010). Also, ATP synthase was one of the dominant proteins expressed over dehydration stress in chickpeas (Jaiswal et al., 2014). Additionally, in Plectus murrayi, bacteria feeding nematode, ATP synthase subunit transcripts were among the abundantly expressed under a desiccated condition (Adhikari et al., 2009).

\section{Cell Wall/Membrane/Envelope Biogenesis}

The genes involved in cell wall/membrane/envelope biogenesis required by $S$. Typhimurium for desiccation survival were $r f b A U$, wzxE, yaeL, pal, lepA, glmS, STM14_0838, and STM14_0839. $r f b A U$ are essential for $\mathrm{O}$ antigen (O polysaccharide) biosynthetic process. Polysaccharides in bacteria may act as a water reservoir in dry terrestrial environments. Garmiri et al. (2008) found that Salmonella spp. lacking $\mathrm{O}$ antigen are more sensitive to desiccation (Garmiri et al., 2008). Additionally, $w z x E$ is involved in translocation of $\mathrm{O}$ antigen. STM14_0838 (putative UDP-galactopyranose mutase) encodes UDP-alpha-Dgalactofuranose required for synthesis of cell wall in bacteria, fungi, and protozoa (http://www.genome.jp/dbget-bin/www bget?ec:5.4.99.9). Furthermore, Escherichia coli yaeL, which encodes a membrane-bound zinc metalloprotease involved in regulated intramembrane proteolysis, is required for activation of sigma factor $\mathrm{E}\left(\sigma^{\mathrm{E}}\right)$ encoded by $r p o E$ gene in response to an envelope stress (Kanehara et al., 2002). Mutation in pal gene (peptidoglycan associated lipoprotein) causes a severe defect in the cell envelope of gram-negative bacteria (Vines et al., 2005). LepA, ribosomal elongation factor 4 (EF4), has two opposing functions in E. coli-promoting survival during moderate stress 


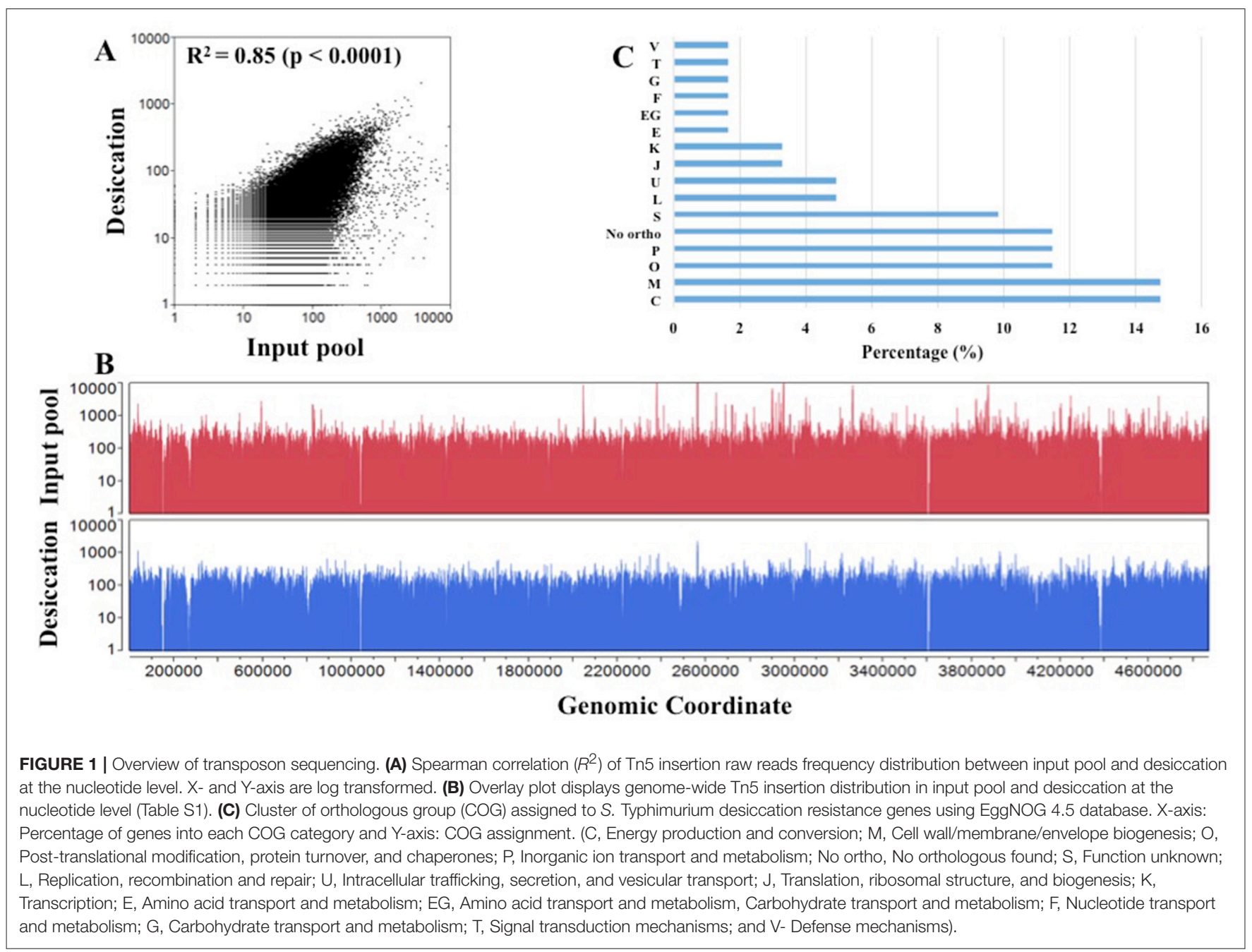

by allowing stress-paused translation to resume and death during severe stress through self-destruction (Li et al., 2014).

\section{Post-translational Modification, Protein Turnover, and Chaperones}

Salmonella desiccation resistance genes belonging to COG "O" category were $d n a J K, d s b C, g l n D$, STM14_3328, STM14_2014, and STM14_2258. DnaK/DnaJ chaperone machinery is required for protein folding and essential for protein repair under both physiological and stressful conditions including heat shock stress (Takaya et al., 2004; Rychlik and Barrow, 2005). E. coli DsbC, a protein required for disulfide bond isomerization in periplasm, assists in folding of several envelope proteins containing disulfides formed between cysteine residues and is involved in the defense mechanism against oxidative stress (Denoncin et al., 2014). E. coli GlnD, a bifunctional uridylyltransferase/uridylylremoving signal-transduction enzyme and the primary sensor of nitrogen status in cell, has a critical role in growth response to either nitrogen limitation or excess. Commonly, nitrogen is an essential chemical for all living being, which is an irreplaceable constituent of protein, DNA, and RNA (Tondervik et al., 2006;
Yurgel et al., 2013). Probably, S. Typhimurium faces nitrogen limitation stress during desiccation in PBS, requiring $g \ln D$ for survival. STM14_2258 (STM1864), a putative inner membrane protein, is regulated by $\mathrm{RcsCDB}$ system, which responds to envelope stress (Mariscotti and Garcia-del Portillo, 2009).

\section{Inorganic Ion Transport and Metabolism}

The Salmonella genes involved in inorganic ion transport and metabolism that are required for desiccation stress survival were fepCDG, pstB, corA, nhaA, and phoU. The fepCDG and $p s t B$ encode ATP-binding cassette $(\mathrm{ABC})$ transporters. In Rhizobium leguminosaurm, a soil bacterium with the ability to fix nitrogen, mutation in an uncharacterized $A B C$ transporter operon (RL2975-RL2977) caused the cell to be highly sensitive to desiccation stress due to significantly lower accumulation of exopolysaccharide (Vanderlinde et al., 2010). FepCDG are iron-enterobactin transporter, a high affinity siderophore that acquires iron for microbial systems (Porcheron et al., 2013). Virtually, iron is a vital nutrient for all forms of life and is required for energy generation, DNA replication, oxygen transport, and protection against oxidative stress (Skaar, 2010). 
TABLE 2 | The protein coding genes of S. Typhimurium 14028S required for desiccation survival.

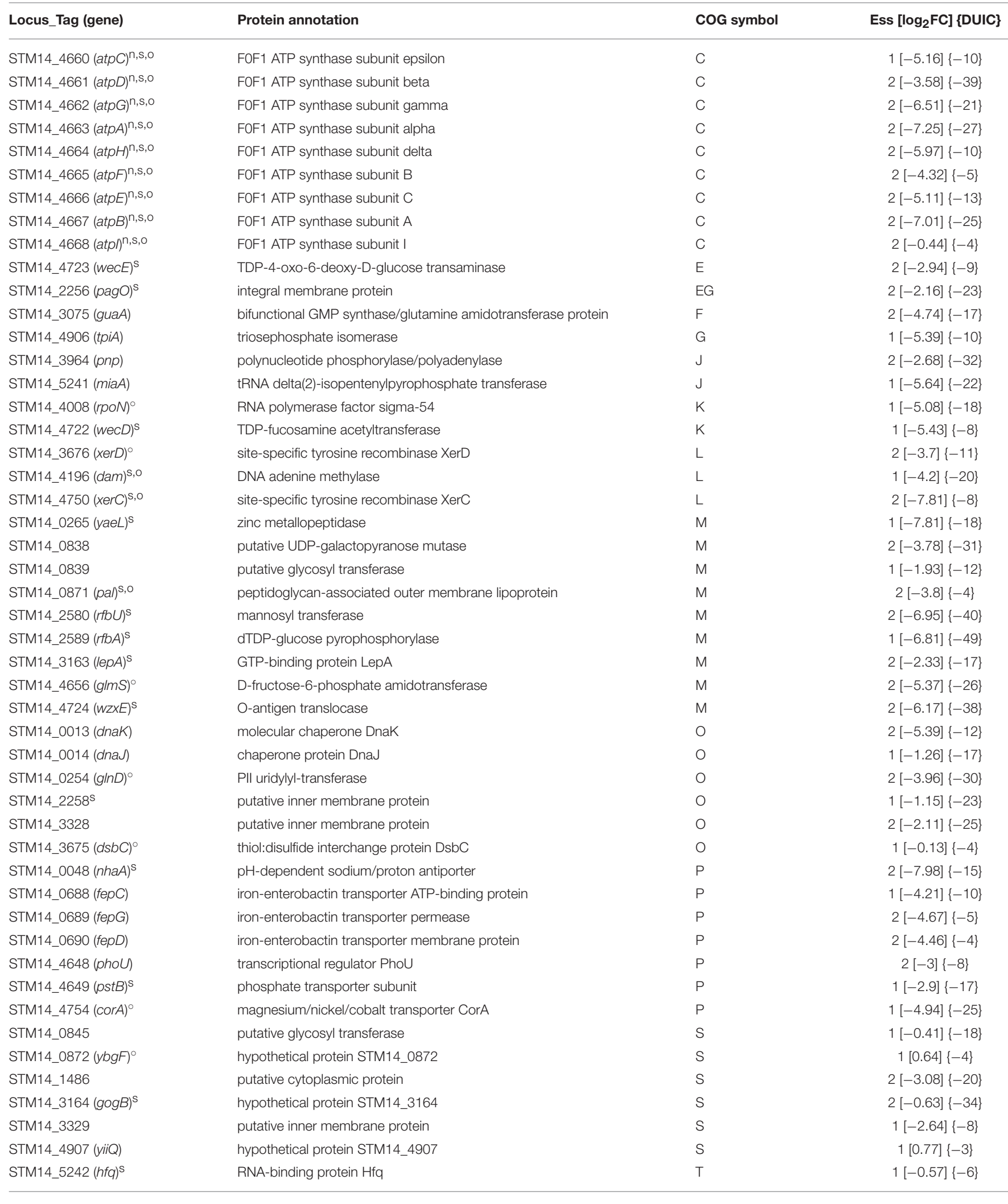


TABLE 2 | Continued

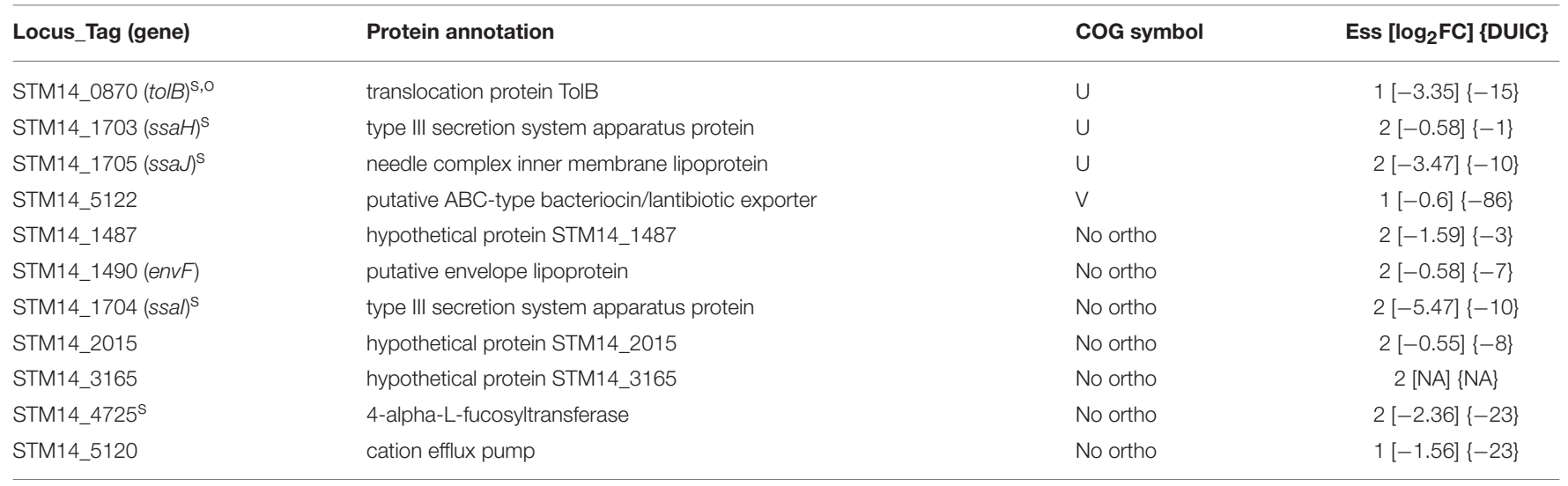

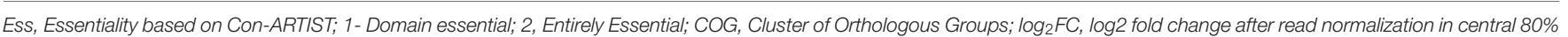

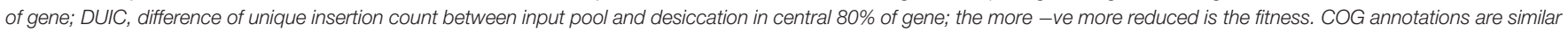

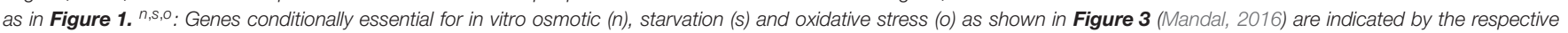
superscripts.

Finn et al. (2013b) showed a number of genes involved in $\mathrm{Fe}-\mathrm{S}$ clusters formation were upregulated during desiccation on a stainless steel surface which were induced under ironlimiting conditions (Finn et al., 2013b). Most bacteria regulate the uptake of inorganic orthophosphate $\left(\mathrm{P}_{\mathrm{i}}\right)$ by a negative regulatory protein $\mathrm{PhoU}$ via $\mathrm{ABC}$ phosphate-specific transporter (Pst). Phosphorous is an essential element in all cells with roles in diverse biological functions ranging from structural and metabolic biological processes to the composition of nucleic acids, phospholipids, and energy intermediates. However, we found only pstB (encoding cytoplasmic ATPase) and phoU were required for survival during desiccation in $S$. Typhimurium. The other three genes involved in $\mathrm{P}_{\mathrm{i}}$ uptake systems includes extracellular $\mathrm{P}_{\mathrm{i}}$ binding proteins $(p s t S)$ and two transmembrane channel proteins ( $p s t C A$ ) (Zheng et al., 2016). This might indicate the possibility of other redundant pathways doing the job of these three genes. Nonetheless, phosphate transport genes (pstACS) were differentially upregulated for the survival of desiccated $S$. Typhimurium on s stainless steel surface (Finn et al., 2013b).

CorA is a magnesium/nickel/cobalt transporter. The corA mutant of Salmonella shows a range of phenotypes including altered expression of Salmonella pathogenicity island 1(SPI-1) genes; decreased tolerance to heat shock and peroxide; defective invasion, survival, and proliferation inside macrophage and epithelial cells; decreased virulence and decreased tolerance to lactoperoxidase enzyme (Sermon et al., 2005). NhaA is $\mathrm{pH}-$ dependent sodium/proton $\left(\mathrm{H}^{+}\right)$antiporter that plays a critical role in intracellular $\mathrm{pH}$ regulation under alkaline conditions, cell volume regulation, and maintenance of electrochemical potential of $\mathrm{Na}^{+}$across cytoplasmic membrane plus other (Vimont and Berche, 2000).

\section{Transcription (K) and Replication, Recombination and Repair (L)}

Salmonella desiccation tolerance gene related to transcription (K) were $r p o N$ and $w e c D$; and replication, recombination, and repair (L) were dam and xerCD. Alternative sigma factor 54 $\left(\sigma^{54}\right.$ : encoded by $\left.r p o N\right)$ plays an important role in the regulation of stress resistance in many bacterial species. E. coli RpoN controls more than 14 operons/regulators during nitrogenlimiting conditions and protects the cells from alkaline $\mathrm{pH}$ during stationary-phase growth (Model et al., 1997; Reitzer and Schneider, 2001). Deletion of rpoN in Listeria monocytogenes affects the ability to grow under osmotic stress (Okada et al., 2006). Importantly, Salmonella Typhi RpoN regulates the expression of $\mathrm{O}$-antigen, a water reservoir, during nitrogen limitation via transcriptional control of $r f a H$ gene (Bittner et al., 2002). Additionally, in Bradyrhizobium japonicum, a nitrogenfixing bacterium, deletion of $\sigma 54$ (rpoN1, rpoN2, and both) led to significant decrease in viability during desiccation stress (Cytryn et al., 2007). WecD, TDP-fucosamine acetyltransferase, is required in the final step for the synthesis of 4-acetamido-4,6dideoxy-d-galactose, a sugar unit of polysaccharide ( $\mathrm{O}$ antigen) which is composed of repeating unit of trisaccharide (Hung et al., 2006).

Dam, DNA adenine methylase, plays important role in DNA replication, DNA mismatch repair and SOS response (a genomewide response to DNA damage where cell cycle is arrested and DNA repair and mutagenesis is active; Stephenson and Brown, 2016). Dam plays a protective role during oxidative stress in S. Typhimurium (Chatti et al., 2012). XerCD are site-specific tyrosine recombinase genes that resolve chromosome dimer (and is lethal if not resolved) at a dif site (Dörr et al., 2009). xerC mutant of Staphylococcus aureus demonstrated limited biofilm formation and attenuated virulence in murine bacteremia model (Atwood et al., 2016).

\section{Other Desiccation Survival Genes}

$\mathrm{Hfq}$, an RNA chaperone protein, has a diverse role in bacterial physiology including growth-dependent metabolism, stress resistance, virulence and drug resistance through posttranscriptional control of gene expression. The most prominent role of Hfq protein in bacteria is in facilitating the interactions between non-coding sRNAs and their cognitive target mRNA 
molecules (De Lay et al., 2013). Although no sRNA genes implicated in desiccation survival has been reported, the importance of $h f q$ gene in desiccation survival of $S$. Typhimurium may suggest the involvement of unknown sRNAs in the process. The 6 intergenic regions identified in this study to be required for desiccation survival may support this hypothesis (see the next section). In Francisella novicida, Hfq protein has an important role in resistance to stresses such as, osmotic change, low $\mathrm{pH}$, heat shock and oxidative stress. Salmonella Hfq protein positively regulates virulence by targeting hilD mRNA that affects secretion of type III secretion system (T3SS) encoded by Salmonella pathogenicity island 1 (SPI-1) (Shakhnovich et al., 2009; Yang et al., 2015). SPI-2 genes (ssaHIJ) encoding T3SS were also required for desiccation survival of Salmonella. TolB, a translocation periplasmic protein, is involved in maintaining the integrity of outer membrane via Tol/Pal system in E. coli (Walburger et al., 2002).

MiaA, a tRNA delta (2)-isopentenyl pyrophosphate transferase gene, is required for the efficient translation of the $\operatorname{rpoS}\left(\sigma^{S}\right)$ mRNA. $\sigma^{\mathrm{S}}$ factor is necessary for the stationary phase/general stress response and required during nutrient starvation and presence of toxic metabolite in E. coli (Thompson and Gottesman, 2014). However, rpoS was not identified as desiccation survival gene in this study. Pnp, a polynucleotide phosphorylase/polyadenylase, provides protection against lactic acid exposure in $S$. Typhimurium. Moreover, $p n p$ mutant in E. coli has a decrease in RpoS-regulated transcripts (Bearson et al., 2006). Null mutations of wecE gene (TDP-4-oxo-6-deoxyD-glucose transaminase) in E. coli responsible for the synthesis of enterobacterial common antigen (ECA), a glycolipid found in the outer leaflet of the outer membrane in all species of family Enterobacteriaceae, confers sensitivity to bile (Danese et al., 1998). PagO, an integral inner membrane protein, is activated by phoPQ regulon. Salmonella PhoPQ is a twocomponent regulatory system that provides protection against host cationic antimicrobial peptides and intracellular survival within acidic phagosomes by regulating outer membrane (OM) acidic glycerophospholipids with lipid A structure (Dalebroux et al., 2014). Salmonella lacking tpiA gene, encoding a glycolytic enzyme triosephosphate isomerase that plays a key role in the central carbon metabolism, has an altered morphology with an elongated shape as compared to the wild type and is required for full in vivo fitness (Paterson et al., 2009).

Additionally, genes encoding putative proteins required for desiccation survival included inner membrane protein (STM14_3329, STM14_2258, and STM14_3328); glycosyl transferase (STM14_0839 and STM14_0845); STM14_1490 (envF, putative envelope protein); STM14_1486 (putative cytoplasmic protein); STM14_2014 (putative thiol peroxidase); and STM14_0838 (putative UDP-galactopyranose mutase). Similarly, S. Typhimurium desiccation tolerance genes encoding hypothetical proteins were STM14_0872 (ybgF), STM14_1487, STM14_2015, STM14_3164 (gogB), STM14_3165, and STM14_4907 (yiiQ). YbgF (ybgC-tolQRAB-pal-ybgF operon) is involved in maintenance of cell envelope integrity. GogB, a phage-encoded effector protein, is an anti-inflammatory effector, which regulates inflammation-enhanced colonization and limits tissue damage during Salmonella infection (Pilar et al., 2012).

\section{Desiccation Resistance Salmonella Intergenic Regions}

We identified six entirely essential intergenic regions of $S$. Typhimurium required for survival in desiccation stress on petri plate (Table 3). To determine if any of these intergenic regions encode non-coding sRNA, genomic DNA sequence was extracted for these intergenic regions and blasted for the presence of small RNA (sRNA) against sRNATarBase 2.0, a database of bacterial sRNA targets verified by experiment (Cao et al., 2010). However, we could not find hit for any known sRNA. There might be novel genetic elements in these intergenic regions of Salmonella genome yet to be explored.

Furthermore, we searched for the presence of coding region in the desiccation resistance intergenic region using GeneMark (http://www.ncbi.nlm.nih.gov/genomes/MICROBES/genemark. cgi). There was no coding sequence in the 5 intergenic regions. Strikingly, IG_STM14_1490 had a coding sequence with start at 1337639 bp and end at 1337842 bp of 204 bp. The result corroborates with PATRIC (Pathosystems Resource Integration Center, www.patricbrc.org) annotation that contains a hypothetical protein (fig|588858.6.peg.1457) on the negative strand. Moreover, we looked for the promoter regions in the desiccation resistance intergenic regions using Pepper (http:// genome2d.molgenrug.nl/index.php/prokaryote-promoters). Interestingly, only IG_STM14_3165 had the predicted promoter.

\section{Phenotypic Evaluation of Single Gene Knockout Mutants}

We performed phenotypic evaluation of 12 single knockout mutants to validate the functional roles of the genes in desiccation survival. Six $S$. Typhimurium knockout mutants were entirely essential $(\Delta n a h A, \Delta a t p G, \Delta a t p H, \Delta s s a j, \Delta l e p A$, and $\Delta p a g O)$ and six were domain essential ( $\Delta \operatorname{cor} A, \Delta p s t B, \Delta$ STM14_2014, $\Delta$ STM14_5120, $\Delta$ STM14_2258, and $\Delta$ STM14_5122). Tn-seq analysis showed the fold change in read numbers $\left[\log _{2}(\mathrm{OP} / \mathrm{IP})\right]$ of mutant strains varied from -7.98 to -0.6 with the difference of unique insertion count (DUIC; unique insertions of OPunique insertions of IP) ranging from -86 to -10 (Table 2) calculated using Tn-Seq Explorer (Solaimanpour et al., 2015). Unique insertion count is the number of genomic loci disrupted

TABLE 3 | The intergenic regions of S. Typhimurium 14028 S required for desiccation survival.

\begin{tabular}{lcccc}
\hline Intergenic region & Start & End & Length (bp) & Essentiality \\
\hline IG_STM14_3329 & $2,923,580$ & $2,923,838$ & 259 & 2 \\
IG_STM14_3165 & $2,782,023$ & $2,782,225$ & 203 & 2 \\
IG_STM14_3164 & $2,780,125$ & $2,780,528$ & 404 & 2 \\
IG_STM14_2257 & $1,971,827$ & $1,971,958$ & 132 & 2 \\
IG_STM14_1490 & $1,337,373$ & $1,338,163$ & 791 & 2 \\
IG_STM14_0255 & 253,521 & 253,756 & 236 & 2 \\
\hline
\end{tabular}

2- Entirely essential as classified by Con-ARTIST pipeline. 
by Tn5 insertion. Mutant survival (\%) was calculated as described in Materials and Methods. The result showed that only five of the mutants demonstrated reduced survival as compared to the wild type and seven strains had higher survival rate than the wild type (Figure 2A). Among the five mutants with reduced desiccation survival, only three mutants $(\triangle a t p H, \triangle a t p G$, and $\Delta c o r A)$ showed statistically significant reduction in survival as compared to the wild type ( $p<0.02$, unpaired $t$-test). To surprise, four mutants had significantly increased survival compared to the wild type $\left(\Delta S T M 14 \_5122, \Delta\right.$ STM14_2258, $\Delta p a g O$, and $\left.\Delta p s t B\right)$ contrary to the results of Tn-seq analysis (Figure 2A). To understand the discrepancy between Tn-seq result and phenotypic data, we inspected Tn5 insertion profiles in IP and OP for these genes. The profiles show significantly reduced read numbers after the selection for each identified gene as shown in Figures 2B-F and Figures S1A-E, corroborating well with the genes identified by the analysis of Tn-seq data. Spearman correlation analysis also indicated that there was a significant correlation between survival (\%) and $\log _{2} \mathrm{FC}\left(R^{2}=0.62, p=0.0307\right)$ as shown in Figure S2.

However, the result of the phenotypic study did not well substantiate the result of Tn-seq analysis for all mutants tested. We speculate that the disagreement is partially due to the differences in the assay conditions for the library selection and phenotypic assay for single mutants. They differ in terms of the context of experimental vessel (petri plate vs. 96 well plate) and cells (library vs. single mutant), drying method, duration of desiccation stress etc. During the process of optimizing the condition for phenotypic assay, we found that the survival rate of the wild type cells fluctuates greatly depending on the parameters used in the assays. Also, if the phenotype is influenced by the factors secreted into media, the phenotypic outcome of a mutant can be different depending on whether it exists in the context of a mutant library or the pure culture of the same mutant cells. Therefore, we expect that the use of further optimized assay condition may provide the results more consistent with the result of Tn-seq analysis for all mutants tested.

\section{Comparative Study}

We have searched for Salmonella genes in literature, which have been associated with desiccation resistance. Major genes involved in desiccation resistance were $\mathrm{K}^{+}$transport channel $k d p F A B C$ transporter, isocitrate-lyase ace A, lipid A biosynthesis palmitoleoyl-acyltransferase $d d g$, iron-sulfur cluster scaffolding protein nifU, global regulator $f n r$, alternative sigma factor rpoE (Gruzdev et al., 2012b), specialized sigma factor rpoS (Finn et al., 2013a), osmoprotectant transporters (proUP and $o s m U$ ) (Finn et al., 2013b), and trehalose biosynthesis genes (ost AB) (Li et al., 2012). All of these genes were disrupted by Tn5 in both IP and OP (Table S3), making

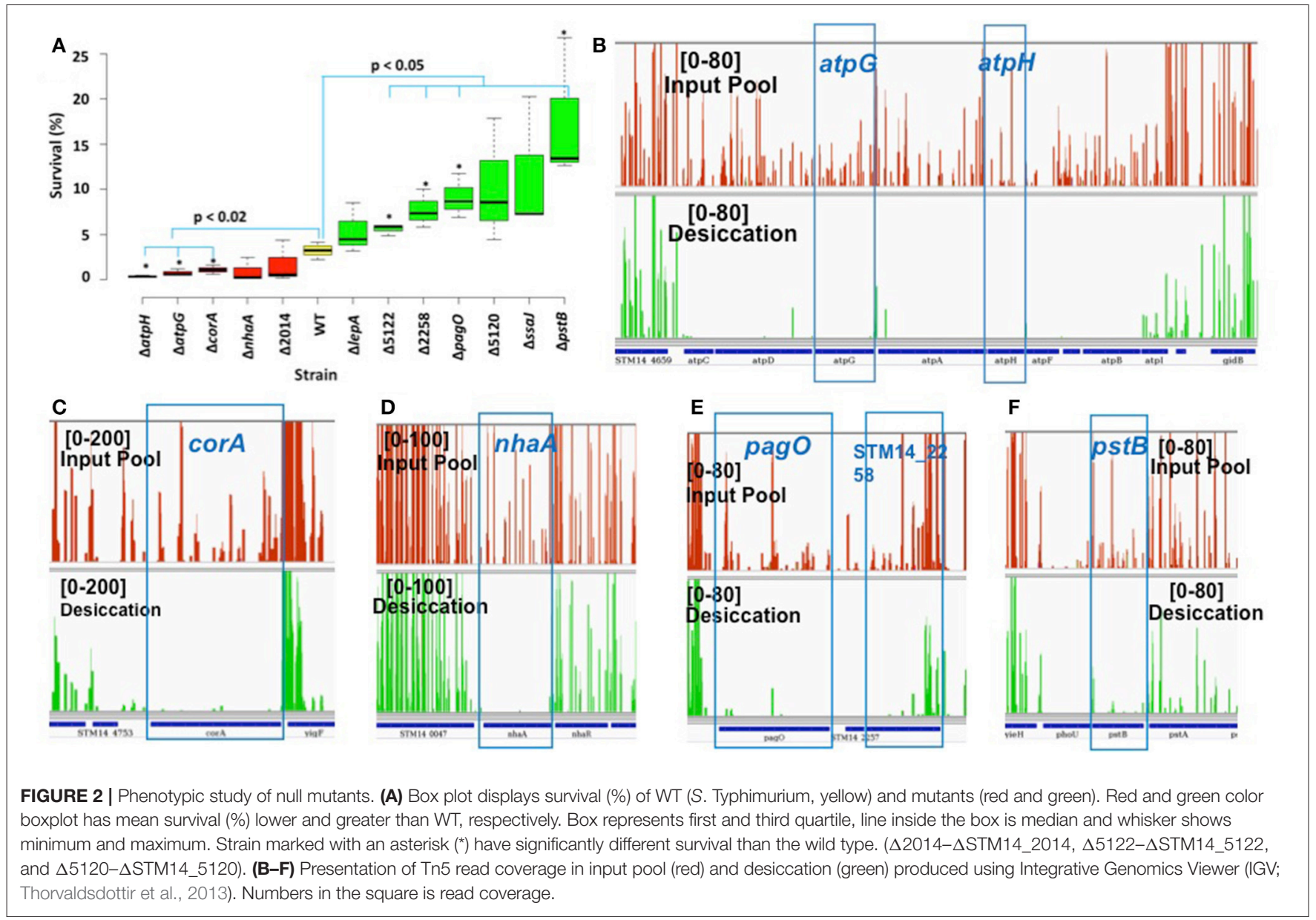




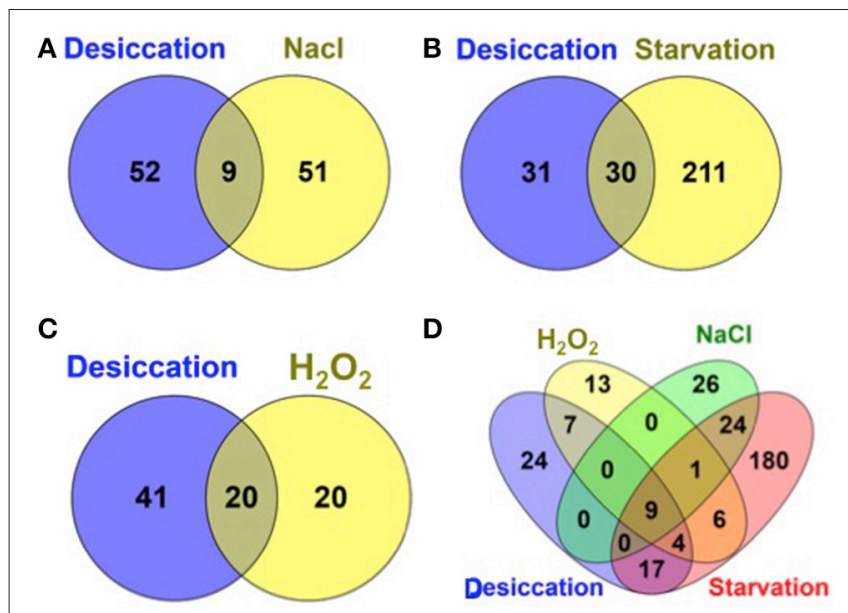

FIGURE 3 | Venn diagram showing a comparison of S. Typhimurium desiccation resistance genes with other environmental stress resistance genes. Desiccation resistance genes compared with previously identified resistance genes (Mandal, 2016) during: (A) osmotic stress $(3 \% \mathrm{NaCl}$ in LB medium); (B) Starvation (starved for 12 days in PBS); (C) oxidative stress (1 mm hydrogen peroxide $\left(\mathrm{H}_{2} \mathrm{O}_{2}\right)$ in LB medium); and (D) all the four stressors.

them non-essential for survival during desiccation in our experimental setting. Furthermore, these mutants were not sensitive to desiccation stress in our study (Figure S3). We speculate that the discrepancy may be due to the differences in multiple factors, including the genetic backgrounds, the experimental settings (stainless steel surface, sterile filter paper or plastic ware), variable desiccation period (couple of hours to weeks), genomic techniques (transcriptome vs. Tn-seq), and/or sensitivity of Con-ARTIST pipeline to identify CEGs. Interestingly, trehalose-negative strains of Cronobacter spp. was shown to survive dry stress as well as the wild type strains, suggesting that the factors for desiccation survival could vary in different genetic backgrounds (Breeuwer, 2014).

Additionally, we compared the desiccation resistance genes with those genes required for resistance against related environmental stresses such as, starvation, osmotic, and oxidative stress encountered during the infection cycle by $S$. Typhimurium from our recent study (Mandal, 2016) as shown in Figure 3. To note, the same IP used in this study was used for all screening against these stress conditions. Interestingly, we found a more than $50 \%$ of desiccation resistance genes were shared by the genes for starvation survival (Salmonella starved for 12 days) and more than $30 \%$ of desiccation resistance genes were shared by the genes required for resistance to hydrogen peroxide $\left(\mathrm{H}_{2} \mathrm{O}_{2}, 1 \mathrm{mM}\right)$ stress. Hence, this may indicate that $S$. Typhimurium experience starvation as well as oxidative stress during desiccation. Additionally, only ATP synthase genes (9 subunit proteins) were shared between desiccation and osmotic stress $(3 \% \mathrm{NaCl})$ that were also required for fitness during starvation and hydrogen peroxide insult (Figure 3). Thus, osmotic stress imposed by $3 \% \mathrm{NaCl}$ is distinct from the osmotic stress incurred by Salmonella during desiccation stress.

\section{CONCLUSION}

For the first time to our knowledge, we performed a genomewide screening of a transposon mutant library to identify desiccation survival genes of $S$. Typhimurium. The precision and accuracy for the identification of CEGs depend on the complexity of the input library, experimental design, and downstream bioinformatics analysis. The outcome of Tnseq data analysis depends on several factors like library normalization (bottleneck, positional read bias, differences in sequencing depth and the stochastic difference in library complexity), annotation dependent analysis and annotationindependent analysis (Chao et al., 2016). In this study, we used Con-ARTIST pipeline that enables the characterization of transposon mutant with annotation-independent approach for discovery of genetic elements at a sub-genic level. We identified 61 protein coding genes and six intergenic regions required for the survival of $S$. Typhimurium during a desiccation stress. The important resistance genes to survive the desiccation stress by $S$. Typhimurium were related to energy production and conversion required to maintain basal metabolism; cell wall/membrane/envelope biogenesis required for production of extracellular polysaccharide; post-translational modification, protein turnover, and chaperones; inorganic ion transport and metabolism for transport of magnesium, nickel, cobalt, sodium, iron and phosphate; replication, recombination and repair to overcome DNA damage; intracellular trafficking, secretion, and vesicular transport; translation, ribosomal structure and biogenesis and transcription. More than 20\% of were either putative or hypothetical genes that helped assign novel functions to previously unknown genes. Few genes related to amino acid, nucleotide and carbohydrate transport and metabolism were also required to survive a desiccation stress encountered by Salmonella. Thus, our study was able to provide novel insights into the underlying mechanisms of desiccation survival of Salmonella. We expect that our findings can be further exploited to develop effective control strategies to control the Salmonella contamination from low water activity foods and food processing facilities.

\section{AUTHOR CONTRIBUTIONS}

YMK: Conceived the study; RKM: performed experiment, analyzed the data, and drafted the manuscript; YMK: revised the manuscript.

\section{ACKNOWLEDGMENTS}

We would like to thank Arkansas Biosciences Institute (ABI) for funding support and Arkansas High Performance Computing Center (AHPCC) - University of Arkansas for their support on bioinformatics analysis.

\section{SUPPLEMENTARY MATERIAL}

The Supplementary Material for this article can be found online at: http://journal.frontiersin.org/article/10.3389/fmicb. 2017.01723/full\#supplementary-material 


\section{REFERENCES}

Adhikari, B. N., Wall, D. H., and Adams, B. J. (2009). Desiccation survival in an antarctic nematode: molecular analysis using expressed sequenced tags. $B M C$ Genomics 10:69. doi: 10.1186/1471-2164-10-69

Atwood, D. N., Beenken, K. E., Loughran, A. J., Meeker, D. G., Lantz, T. L., Graham, J. W., et al. (2016). XerC contributes to diverse forms of Staphylococcus aureus infection via agr-dependent and agr-independent pathways. Infect. Immun. 84, 1214-1225. doi: 10.1128/IAI.01462-15

Bearson, S. M., Bearson, B. L., and Rasmussen, M. A. (2006). Identification of Salmonella enterica serovar Typhimurium genes important for survival in the swine gastric environment. Appl. Environ. Microbiol. 72, 2829-2836. doi: 10.1128/AEM.72.4.2829-2836.2006

Bell, C., and Kyriakides, A. (2008). Salmonella: A Practical Approach to the Organism and Its Control in Foods. London, UK: John Wiley \& Sons. Available online at: https://books.google.com/books/about/Salmonella.html?id= XbuSAdk-sIC\&printsec $=$ frontcover\&source $=k p \_r e a d \_b u t t o n \# v=$ onepage $\&$ $\mathrm{q} \& \mathrm{f}=$ false

Beuchat, L. R., and Heaton, E. K. (1975). Salmonella survival on pecans as influenced by processing and storage conditions. Appl. Microbiol. 29, 795-801.

Beuchat, L. R., Komitopoulou, E., Beckers, H., Betts, R. P., Bourdichon, F., Fanning, S., et al. (2013). Low-water activity foods: increased concern as vehicles of foodborne pathogens. J. Food Prot. 76, 150-172. doi: 10.4315/0362-028X.JFP-12-211

Bittner, M., Saldías, S., Estévez, C., Zaldívar, M., Marolda, C. L., Valvano, M. A et al. (2002). O-antigen expression in Salmonella enterica serovar typhi is regulated by nitrogen availability through $\mathrm{RpoN}$-mediated transcriptional control of the rfaH gene. Microbiology 148, 3789-3799. doi: 10.1099/00221287-148-12-3789

Braun, P., Fehlhaber, K., and Wicke, A. (1999). Salmonella enteritidis invades the egg through the shell. World Poult Special 23-24. Available online at: https:// scholar.google.com/scholar?hl=en\&q=Salmonella+enteritidis+invades+the+ egg+through+the+shell.+World+Poult+Special.\&btnG=\&as_sdt=1\%2C18\& as_sdtp=

Breeuwer, P. (2014). "Adaptation of pathogenic microorganisms to dry conditions," in The Microbiological Safety of Low Water Activity Foods and Spices, eds J. B. Gurtler, M. P. Doyle, and J. L. Kornacki (New York, NY: Springer), 37-48.

Cao, Y., Wu, J., Liu, Q., Zhao, Y., Ying, X., Cha, L., et al. (2010). sRNATarBase: a comprehensive database of bacterial sRNA targets verified by experiments. RNA 16, 2051-2057. doi: 10.1261/rna.2193110

Chao, M. C., Abel, S., Davis, B. M., and Waldor, M. K. (2016). The design and analysis of transposon insertion sequencing experiments. Nat. Rev. Microbiol. 14, 119-128. doi: 10.1038/nrmicro.2015.7

Chatti, A., Messaoudi, N., Mihoub, M., and Landoulsi, A. (2012). Effects of hydrogen peroxide on the motility, catalase and superoxide dismutase of dam and/or seqA mutant of Salmonella Typhimurium. World J. Microbiol. Biotechnol. 28, 129-133. doi: 10.1007/s11274-011-0801-8

Cytryn, E. J., Sangurdekar, D. P., Streeter, J. G., Franck, W. L., Chang, W. S., Stacey, G., et al. (2007). Transcriptional and physiological responses of Bradyrhizobium japonicum to desiccation-induced stress. J. Bacteriol. 189, 6751-6762. doi: 10.1128/JB.00533-07

Dalebroux, Z. D., Matamouros, S., Whittington, D., Bishop, R. E., and Miller, S. I. (2014). PhoPQ regulates acidic glycerophospholipid content of the Salmonella Typhimurium outer membrane. Proc. Natl. Acad. Sci. U.S.A. 111, 1963-1968. doi: 10.1073/pnas.1316901111

Danese, P. N., Oliver, G. R., Barr, K., Bowman, G. D., Rick, P. D., and Silhavy, T. J. (1998). Accumulation of the enterobacterial common antigen lipid II biosynthetic intermediate stimulates degP transcription in Escherichia coli. J. Bacteriol. 180, 5875-5884.

Dawoud, T. M., Jiang, T., Mandal, R. K., Ricke, S. C., and Kwon, Y. M. (2014). Improving the efficiency of transposon mutagenesis in Salmonella enteritidis by overcoming host-restriction barriers. Mol. Biotechnol. 56, 1004-1010. doi: 10.1007/s12033-014-9779-4

De Lay, N., Schu, D. J., and Gottesman, S. (2013). Bacterial small RNA-based negative regulation: Hfq and its accomplices. J. Biol. Chem. 288, 7996-8003. doi: $10.1074 /$ jbc.R112.441386
Deng, X., Li, Z., and Zhang, W. (2012). Transcriptome sequencing of Salmonella enterica serovar Enteritidis under desiccation and starvation stress in peanut oil. Food Microbiol. 30, 311-315. doi: 10.1016/j.fm.2011.11.001

Denoncin, K., Vertommen, D., Arts, I. S., Goemans, C. V., Rahuel-Clermont, S., Messens, J., et al. (2014). A new role for Escherichia coli DsbC protein in protection against oxidative stress. J. Biol. Chem. 289, 12356-12364. doi: $10.1074 /$ jbc.M114.554055

Dörr, T., Lewis, K., and Vulić, M. (2009). SOS response induces persistence to fluoroquinolones in Escherichia coli. PLoS Genet. 5:e1000760. doi: 10.1371/journal.pgen.1000760

Farakos, S. M. S., and Frank, J. F. (2014). "Challenges in the control of foodborne pathogens in low-water activity foods and spices," in The Microbiological Safety of Low Water Activity Foods and Spices, eds J. B. Gurtler, M. P. Doyle, and J. L. Kornacki (New York, NY: Springer), 15-34.

Finn, S., Condell, O., McClure, P., Amézquita, A., and Fanning, S. (2013a). Mechanisms of survival, responses and sources of Salmonella in low-moisture environments. Front. Microbiol. 4:331. doi: 10.3389/fmicb.2013.00331

Finn, S., Handler, K., Condell, O., Colgan, A., Cooney, S., McClure, P., et al. (2013b). ProP is required for the survival of desiccated Salmonella enterica serovar Typhimurium cells on a stainless steel surface. Appl. Environ. Microbiol. 79, 4376-4384. doi: 10.1128/AEM.00515-13

Finn, S., Rogers, L., Handler, K., McClure, P., Amezquita, A., Hinton, J. C., et al. (2015). Exposure of Salmonella enterica serovar Typhimurium to three humectants used in the food industry induces different osmoadaptation systems. Appl. Environ. Microbiol. 81, 6800-6811. doi: 10.1128/AEM.01379-15

Garmiri, P., Coles, K. E., Humphrey, T. J., and Cogan, T. A. (2008). Role of outer membrane lipopolysaccharides in the protection of Salmonella enterica serovar Typhimurium from desiccation damage. FEMS Microbiol. Lett. 281, 155-159. doi: 10.1111/j.1574-6968.2008.01093.x

Gruzdev, N., McClelland, M., Porwollik, S., Ofaim, S., Pinto, R., and SaldingerSela, S. (2012b). Global transcriptional analysis of dehydrated Salmonella enterica serovar Typhimurium. Appl. Environ. Microbiol. 78, 7866-7875. doi: 10.1128/AEM.01822-12

Gruzdev, N., Pinto, R., and Sela, S. (2011). Effect of desiccation on tolerance of Salmonella enterica to multiple stresses. Appl. Environ. Microbiol. 77, 1667-1673. doi: 10.1128/AEM.02156-10

Gruzdev, N., Pinto, R., and Sela, S. (2012a). Persistence of Salmonella enterica during dehydration and subsequent cold storage. Food Microbiol. 32, 415-422. doi: $10.1016 /$ j.fm.2012.08.003

Hiramatsu, R., Matsumoto, M., Sakae, K., and Miyazaki, Y. (2005). Ability of shiga toxin-producing Escherichia coli and Salmonella spp. to survive in a desiccation model system and in dry foods. Appl. Environ. Microbiol. 71, 6657-6663. doi: 10.1128/AEM.71.11.6657-6663.2005

Hung, M. N., Rangarajan, E., Munger, C., Nadeau, G., Sulea, T., and Matte, A. (2006). Crystal structure of TDP-fucosamine acetyltransferase (WecD) from Escherichia coli, an enzyme required for enterobacterial common antigen synthesis. J. Bacteriol. 188, 5606-5617. doi: 10.1128/JB.00 306-06

Jaiswal, D. K., Mishra, P., and Subba, P. (2014). Membrane-associated proteomics of chickpea identifies Sad1/UNC-84 protein (CaSUN1), a novel component of dehydration signaling. Sci. Rep. 4, 1-10. doi: 10.1038/srep04177

Kanehara, K., Ito, K., and Akiyama, Y. (2002). YaeL (EcfE) activates the $\sigma$ E pathway of stress response through a site-2 cleavage of anti-øe, RseA. Genes Dev. 16, 2147-2155. doi: 10.1101/gad.1002302

Komitopoulou, E., and Peñaloza, W. (2009). Fate of Salmonella in dry confectionery raw materials. J. Appl. Microbiol. 106, 1892-1900. doi: 10.1111/j.1365-2672.2009.04144.x

Kotzekidou, P. (1998). Microbial stability and fate of Salmonella enteritidis in halva, a low-moisture confection. J. Food Prot. 61, 181-185. doi: 10.4315/0362-028X-61.2.181

Langmead, B., Trapnell, C., Pop, M., and Salzberg, S. L. (2009). Ultrafast and memory-efficient alignment of short DNA sequences to the human genome. Genome Biol. 10:R25. doi: 10.1186/gb-2009-10-3-r25

Li, H., Bhaskara, A., Megalis, C., and Tortorello, M. L. (2012). Transcriptomic analysis of Salmonella desiccation resistance. Foodborne Pathog. Dis. 9, 1143-1151. doi: 10.1089/fpd.2012.1254 
Li, L., Hong, Y., Luan, G., Mosel, M., Malik, M., Drlica, K., et al. (2014). Ribosomal elongation factor 4 promotes cell death associated with lethal stress. MBio 5:e01708-14. doi: 10.1128/mBio.01708-14

Mandal, R. K. (2016). Genetic Determinants of Salmonella and Campylobacter Required for in vitro Fitness. Ph. D. dissertation, University of Arkansas, Fayetteville, AR.

Mariscotti, J. F., and Garcia-del Portillo, F. (2009). Genome expression analyses revealing the modulation of the Salmonella rcs regulon by the attenuator IgaA. J. Bacteriol. 191, 1855-1867. doi: 10.1128/JB.01604-08

Mitchell, A., Romano, G. H., Groisman, B., Yona, A., Dekel, E., Kupiec, M., et al. (2009). Adaptive prediction of environmental changes by microorganisms. Nature 460, 220-224. doi: 10.1038/nature08112

Model, P., Jovanovic, G., and Dworkin, J. (1997). The Escherichia coli phage-shock-protein (psp) operon. Mol. Microbiol. 24, 255-261. doi: 10.1046/j.1365-2958.1997.3481712.x

Nouri, M., and Komatsu, S. (2010). Comparative analysis of soybean plasma membrane proteins under osmotic stress using gel-based and LC MS/MS-based proteomics approaches. Proteomics 10, 1930-1945. doi: $10.1002 /$ pmic. 200900632

Okada, Y., Okada, N., Makino, S., Asakura, H., Yamamoto, S., and Igimi, S. (2006). The sigma factor RpoN (sigma54) is involved in osmotolerance in Listeria monocytogenes. FEMS Microbiol. Lett. 263, 54-60. doi: 10.1111/j.1574-6968.2006.00405.x

Paterson, G. K., Cone, D. B., Northen, H., Peters, S. E., and Maskell, D. J. (2009). Deletion of the gene encoding the glycolytic enzyme triosephosphate isomerase (tpi) alters morphology of Salmonella enterica serovar Typhimurium and decreases fitness in mice. FEMS Microbiol. Lett. 294, 45-51. doi: 10.1111/j.1574-6968.2009.01553.x

Pilar, A. V. C., Reid-Yu, S. A., Cooper, C. A., Mulder, D. T., and Coombes, B. K. (2012). GogB is an anti-inflammatory effector that limits tissue damage during Salmonella infection through interaction with human FBXO22 and Skp1. PLoS Pathog. 8:e1002773. doi: 10.1371/journal.ppat.1002773

Porcheron, G., Garénaux, A., Proulx, J., Sabri, M., and Dozois, C. M. (2013). Iron, copper, zinc, and manganese transport and regulation in pathogenic enterobacteria: correlations between strains, site of infection and the relative importance of the different metal transport systems for virulence. Front. Cell. Infect. Microbiol. 3:90. doi: 10.3389/fcimb.2013.00090

Porwollik, S., Santiviago, C. A., Cheng, P., Long, F., Desai, P., Fredlund, J., et al. (2014). Defined single-gene and multi-gene deletion mutant collections in Salmonella enterica sv Typhimurium. PLoS ONE 9:e99820. doi: 10.1371/journal.pone.0099820

Pritchard, J. R., Chao, M. C., Abel, S., Davis, B. M., Baranowski, C., Zhang, Y. J., et al. (2014). ARTIST: high-resolution genome-wide assessment of fitness using transposon-insertion sequencing. PLoS Genet. 10:e1004782. doi: 10.1371/journal.pgen.1004782

Reitzer, L., and Schneider, B. (2001). Metabolic context and possible physiological themes of sigma (54)-dependent genes in Escherichia coli. MMBR 65, 422-444. doi: 10.1128/MMBR.65.3.422-444.2001

Rychlik, I., and Barrow, P. A. (2005). Salmonella stress management and its relevance to behaviour during intestinal colonisation and infection. FEMS Microbiol. Rev. 29, 1021-1040. doi: 10.1016/j.femsre.2005.03.005

Sermon, J., Wevers, E. M., Jansen, L., De Spiegeleer, P., Vanoirbeek, K., Aertsen, A., et al. (2005). CorA affects tolerance of Escherichia coli and Salmonella enterica serovar Typhimurium to the lactoperoxidase enzyme system but not to other forms of oxidative stress. Appl. Environ. Microbiol. 71, 6515-6523. doi: 10.1128/AEM.71.11.6515-6523.2005

Shakhnovich, E. A., Davis, B. M., and Waldor, M. K. (2009). Hfq negatively regulates type III secretion in EHEC and several other pathogens. Mol. Microbiol. 74, 347-363. doi: 10.1111/j.1365-2958.2009.06856.x

Skaar, E. P. (2010). The battle for iron between bacterial pathogens and their vertebrate hosts. PLoS Pathog. 6:e1000949. doi: 10.1371/journal.ppat.1000949

Solaimanpour, S., Sarmiento, F., and Mrázek, J. (2015). Tn-seq explorer: a tool for analysis of high-throughput sequencing data of transposon mutant libraries. PLoS ONE 10:e0126070. doi: 10.1371/journal.pone.0126070
Spector, M. P., and Kenyon, W. J. (2012). Resistance and survival strategies of Salmonella enterica to environmental stresses. Food Res. Int. 45, 455-481. doi: 10.1016/j.foodres.2011.06.056

Stephenson, S. A., and Brown, P. D. (2016). Epigenetic influence of dam methylation on gene expression and attachment in uropathogenic Escherichia coli. Front. Public Health 4:131. doi: 10.3389/fpubh.2016.00131

Tagkopoulos, I., Liu, Y. C., and Tavazoie, S. (2008). Predictive behavior within microbial genetic networks. Science 320, 1313-1317. doi: $10.1126 /$ science. 1154456

Takaya, A., Tomoyasu, T., Matsui, H., and Yamamoto, T. (2004). The DnaK/DnaJ chaperone machinery of Salmonella enterica serovar Typhimurium is essential for invasion of epithelial cells and survival within macrophages, leading to systemic infection. Infect. Immun. 72, 1364-1373. doi: 10.1128/IAI.72.3.1364-1373.2004

Thompson, K. M., and Gottesman, S. (2014). The MiaA tRNA modification enzyme is necessary for robust RpoS expression in Escherichia coli. J. Bacteriol. 196, 754-761. doi: 10.1128/JB.01013-13

Thorvaldsdottir, H., Robinson, J. T., and Mesirov, J. P. (2013). Integrative genomics viewer (IGV): high-performance genomics data visualization and exploration Brief Bioinform. 14, 178-192. doi: 10.1093/bib/bbs017

Tondervik, A., Torgersen, H. R., Botnmark, H. K., and Strom, A. R. (2006). Transposon mutations in the 5 ' end of glnD, the gene for a nitrogen regulatory sensor, that suppress the osmosensitive phenotype caused by otsBA lesions in Escherichia coli. J. Bacteriol. 188, 4218-4226. doi: 10.1128/JB.00513-05

Uesugi, A. R., Danyluk, M. D., and Harris, L. J. (2006). Survival of Salmonella enteritidis phage type 30 on inoculated almonds stored at- 20, 4, 23, and 35 C. J. Food Prot. 69, 1851-1857. doi: 10.4315/0362-028X-69.8.1851

Vanderlinde, E. M., Harrison, J. J., Muszynski, A., Carlson, R. W., Turner, R. J., and Yost, C. K. (2010). Identification of a novel ABC transporter required for desiccation tolerance, and biofilm formation in Rhizobium leguminosarum bv. viciae 3841. FEMS Microbiol. Ecol. 71, 327-340. doi: 10.1111/j.1574-6941.2009.00824.x

Vimont, S., and Berche, P. (2000). NhaA, an na(+)/H(+) antiporter involved in environmental survival of Vibrio cholerae. J. Bacteriol. 182, 2937-2944. doi: 10.1128/JB.182.10.2937-2944.2000

Vines, E. D., Marolda, C. L., Balachandran, A., and Valvano, M. A. (2005). Defective O-antigen polymerization in tolA and pal mutants of Escherichia coli in response to extracytoplasmic stress. J. Bacteriol. 187, 3359-3368. doi: 10.1128/JB.187.10.3359-3368.2005

Walburger, A., Lazdunski, C., and Corda, Y. (2002). The Tol/Pal system function requires an interaction between the C-terminal domain of TolA and the N-terminal domain of TolB. Mol. Microbiol. 44, 695-708. doi: 10.1046/j.1365-2958.2002.02895.x

Yang, G., Wang, L., Wang, Y., Li, P., Zhu, J., Qiu, S., et al. (2015). Hfq regulates acid tolerance and virulence by responding to acid stress in Shigella flexneri. Res. Microbiol. 166, 476-485. doi: 10.1016/j.resmic.2015.06.007

Yurgel, S. N., Rice, J., and Kahn, M. L. (2013). Transcriptome analysis of the role of $\mathrm{G} \ln \mathrm{D} / \mathrm{G} \ln B K$ in nitrogen stress adaptation by Sinorhizobium meliloti Rm1021. PLoS ONE 8:e58028. doi: 10.1371/journal.pone.0058028

Zheng, J. J., Sinha, D., Wayne, K. J., and Winkler, M. E. (2016). Physiological roles of the dual phosphate transporter systems in low and high phosphate conditions and in capsule maintenance of Streptococcus pneumoniae D39. Front. Cell. Infect. Microbiol. 6:63. doi: 10.3389/fcimb.2016.00063

Conflict of Interest Statement: The authors declare that the research was conducted in the absence of any commercial or financial relationships that could be construed as a potential conflict of interest.

Copyright (c) 2017 Mandal and Kwon. This is an open-access article distributed under the terms of the Creative Commons Attribution License (CC BY). The use, distribution or reproduction in other forums is permitted, provided the original author(s) or licensor are credited and that the original publication in this journal is cited, in accordance with accepted academic practice. No use, distribution or reproduction is permitted which does not comply with these terms. 